\title{
Penerapan Metode AHP Untuk Membantu Siswa Memilih Jurusan Yang Tepat Di SMK
}

\author{
Frieyadie $^{\mathrm{a}}$, Surya Mahendra Ramadhan ${ }^{\mathrm{b}}$ \\ a'Sistem Informasi, STMIK Nusa Mandiri Jakarta, frieyadie@ nusamandiri.ac.id \\ ${ }^{\mathrm{b}}$ Sistem Informasi, STMIK Nusa Mandiri Jakarta, mahendrasurya6@ gmail.com
}

\begin{abstract}
Students of junior high school who are planning to continue their education to Vocational High School (SMK) must decide the choice. Most of them are less mature to choose the majors that exist according to their ability, due to quite a lot of new students who fail in the middle of the road when they have been accepted in the vocational school. The results of the analysis of the calculation of the results of the AHP method states that the chosen alternative and most appropriate to the criteria is Broadcast. AHP results obtained from 3 respondents who then calculated and obtained the final result that Broadcast excels with a percentage value of $43 \%$ versus Accounting $27 \%$ and $31 \%$ Office Administration. Globally the most important factor prioritized in the selection of majors is the test score with a weighted value of 0.473 or $47 \%$ and the most priority majors are Broadcast majors with a score of 47\%. The AHP method can help schools in particular to determine some issues regarding the selection of majors. Because the AHP method is a method whose main input is human perception.
\end{abstract}

Keywords: Choosing Department, Vocational High School, Analytical Hierarchy Process, AHP

\begin{abstract}
Abstrak
Siswa/i lulusan SMP yang berencana melanjutkan jenjang pendidikannya ke Sekolah Menengah Kejuruan (SMK) harus memutuskan pilihan. Kebanyakan mereka kurang matang untuk memilih jurusan yang ada sesuai kemampuanya, akibat cukup banyak siswa baru yang gagal di tengah jalan ketika mereka sudah diterima di SMK. Hasil analisis dari perhitungan hasil metode AHP menyatakan bahwa alternatif yang terpilih dan paling sesuai dengan kriteria adalah Broadcast. Hasil AHP yang diperoleh dari 3 responden yang kemudian dihitung dan didapat hasil akhir bahwa Broadcast unggul dengan presentase nilai sebesar $43 \%$ berbanding dengan Akuntansi 27\% dan Administrasi Perkantoran 31\%. Secara global faktor utama yang paling di prioritaskan dalam penilaian pemilihan jurusan adalah nilai tes dengan nilai bobot 0,473 atau $47 \%$ dan jurusan yang paling di prioritaskan adalah jurusan Broadcast dengan nilai 47\%. Metode AHP dapat membantu sekolah khususnya untuk menentukan beberapa persoalan mengenai pemilihan jurusan. Karena metode AHP yaitu suatu metode yang input utamannya adalah persepsi manusia.
\end{abstract}

Kata kunci: Memilih Jurusan, Sekolah Menengah Kejurusan, Analytical Hierarchy Process, AHP

(C) 2018 Jurnal RESTI

\section{Pendahuluan}

Setiap tahun, siswa lulusan SMP yang berencana melanjutkan jenjang pendidikannya ke sekolah menengah kejuruan (SMK) harus memutuskan pilihan, ke bidang atau jurusan apa yang akan dipilih untuk melanjutkan pendidikannya kelak. Dan ini adalah sesuatu yang cukup sulit untuk diputuskan [1] dan Pada Sekolah Menengah Kejuruan (SMK) dalam hal kurang matang [2] oleh kebanyakan siswa SMP, pemilihan jurusan bagi siswa-siswi dilakukan dengan terutama yang tidak banyak memiliki referensi dan cara memberikan test ujian soal terlebih dahulu untuk mencari informasi terkait dengan pendidikan SMK. para siswa-siswi nya, seperti Matematika, Bahasa Keputusan pemilihan jurusan para siswa, terkadang Indonesia, serta Bahasa Inggris. Siswa juga bisa dipengaruhi oleh pendapat orang tua [3], teman atau menentukan jurusan sesuai minat dan potensinya figur-figur yang diidolakan [4]. Dengan hanya sendiri, akan tetapi harus berkonsultasi terlebih dahulu mendasarkan pendapat tersebut dan tanpa menelaah dengan guru Bimbingan Konseling (BK) dan jumlah kemampuannya seorang siswa bisa membuat keputusan jurusan yang ada pada sekolah SMK terdiri dari tiga

yang sangat bertolak belakang [5] dengan kemampuan, minat, bakat dan kepribadiannya [6]. Akibat yang buruk terjadi setelah itu yaitu keengganan belajar [1] dan menurunnya kualitas serta menurunnya prestasi akademik [7] karena siswa merasa salah dalam memilih

Diterima Redaksi : 02-05-2018 | Selesai Revisi : 13-08-2018 | Diterbitkan Online : 13-12-2018 
jurusan yaitu Administrasi Perkantoran, Akutansi dan Broadcasting.

Kebanyakan mereka kurang matang untuk memilih jurusan [8] yang ada sesuai kemampuanya, akibat cukup banyak siswa baru yang gagal [9] di tengah jalan ketika mereka sudah diterima di Sekolah Menengah Kejuruan (SMK), Banyak juga kasus siswa yang merasa tidak cocok dengan jurusan yang dipilihnya [10] ketika ia telah memperoleh pelajaran sekolah, jelas ini sangat merugikan bagi kedua pihak [9] antara siswa dengan pihak sekolah.

Tujuan dari penelitian ini sebagai alternative untuk membantu pihak sekolah dalam menentukan keputusan pemilihan jurusan siswa sesuai dengan kriteria. Melakukan penilaian dari setiap kreteria untuk
pemilihan jurusan dan menjadikan suatu Pendukung Keputusan untuk pemilihan jurusan agar mendapatkan siswa yang memenuhi kriteria dengan cepat dan tepat.

\section{Tinjauan Pustaka}

\subsection{Sistem Penunjang Keputusan}

Sistem pendukung keputusan merupakan sistem membaginya dengan jumlah elemen untuk informasi interaktif yang menyediakan informasi, mendapatkan nilai rata-rata; d) Mengukur Konsistensi, pemodelan, dan pemanipulasian data. Sistem dikarena kita tidak menginginkan keputusan penunjang keputusan ini digunakan untuk membantu berdasarkan pertimbangan dengan konsistensi yang para pengambil keputusan untuk menentukan rendah.

keputusan yang tepat dalam situasi yang semi terstruktur dan situasi yang tidak terstruktur. Dalam hal ini para pengambil keputusan tidak tau bagaimana secara pasti bagaimana keputusan seharusnya dibuat.

Menurut Davis dalam Hartono [11] mengemukakan bahwa "Terdapat dua model pengambilan keputusan, yaitu model sistem tertutup dan model sistem terbuka". Model sistem tertutup dilandasi asumsi bahwa bagi diatas dengan banyaknya elemen yang ada, keputusan dapat diambil tanpa campur tangan dari hasilnya disebut $\lambda$ maks. Hitung Consistency Index lingkungan (luar) sistem, karena sistem pengambilan (CI) dengan rumus:

keputusan tidak dipengaruhi oleh lingkungan [11].

Dalam hal ini sistem pengambilan keputusan dianggap $\mathrm{CI}=\frac{(\lambda \text { maks }-\mathrm{n})}{n}$

mengetahui semua alternatif tindakan untuk $\mathrm{n}=$ banyaknya elemen

menanggapi permasalahan dengan segala

konsekuensinya, memiliki metode untuk menyusun Hitung Rasio konsistensi/Consistency Ratio

alternatif-alternatif sesuai prioritasnya, dan dapat dengan menggunakan rumus:

memilih/menetapkan alternatif yang paling

menguntungkan, misalnya dari segi laba, manfaat, dan $\mathrm{CR}=\frac{C I}{R C}$
lain-lain.

Model sistem terbuka dilandasi asumsi bahwa sistem $\mathrm{CR}=$ Consistency Ratio pengambilan keputusan dan lingkungan memiliki $\mathrm{CI}=$ Consistency Index hubungan saling pengaruh [11]. Keputusan yang IR = Index Random Consistency diambil akan berdampak terhadap lingkungan dan sebaliknya lingkungan juga berpengaruh terhadap sistem pengambilan keputusan.

\subsection{Algoritma AHP}

Algoritma dalam menggunakan metode AHP pada dasarnya, prosedur atau langkah-langkah dalam metode
Memeriksa konsistensi hierarki. Jika nilaianya lebih dari $10 \%$, maka peniaian data judgement harus diperbaiki. Namun jika rasio konsistensi (CI/IR) kurang atau sama dengan 0,1 , maka hasil perhitungan bisa dinyatakan benar.

Jurnal RESTI (Rekayasa Sistem dan Teknologi Informasi) Vol . 2 No. 3 (2018) 662 - 667 


\section{Metodologi Penelitian}

\subsection{Tahapan Penelitian}

Tahapan penelitian kajian tentang penerapan metode AHP (Analytical Hierarchy Process) dalam pemilihan jurusan di SMK dijelaskan secara umum sebagai berikut:

a) Survey Literatur, dalam tahap awal ini, peneliti melakukan pengumpulan berupa bahan literatur dan informasi terkait.

b) Identifikasi Masalah, dengan melanjutkan $G=\sqrt[n]{x_{1} x_{2} \ldots x_{n}}$ penelitian dengan cara melakukan identifikasi tentang masalah yang akan dibahas, berkaitan dengan penerapan metode AHP (Analytical Hierarchy Process) dalam pemilihan jurusan di SMK berdasarkan literatur dan informasi yang diperoleh;

c) Studi Pustaka, cara ini peneliti mempelajari literatur berupa buku-buku teori tentang Sistem Pendukung Keputusan, Metode penelitian, AHP, dan jurnal-jurnal yang akan digunakan sebagai kajian teori dalam penelitian.

Menentukan hipotesis awal; Menentukan Variabel dan Sumber Data dengan menentukan variabel-variabel dari penerapan metode AHP (Analytical Hierarchy Process) dan berdasarkan pakar dalam pemilihan jurusan di SMK Sumpah Pemuda. Adapun kriteria dari pemilihan jurusan adalah : potensi, minat dan nilai test. Kemudian menentukan data-data seperti apa yang dibutuhkan berdasarkan populasi, sampel dan cara pengambilan sampel. Kemudian menentukan subjek penelitian; Observasi Lapangan dan Perijinan dengan secara langsung datang ke SMK dan meminta izin kepada pihak-pihak terkait dan berwenang di dalam sekolah SMK Sumpah Pemuda, seperti Kepala Sekolah dan kepala bagian masing masing jurusan di SMK Sumpah Pemuda; Mengumpulkan Data dengan memberikan kuesioner kepada para pakar untuk mendapatkan data yang dibutuhkan untuk membuat statistik Analytical Hierarchy Process (AHP), Analisis data, dengan menganalisis dan mengolah data yang didapat berdasarkan hasil penelitian literatur dan teori-teori yang ada; terakhir menarik sebuah kesimpulan berdasarkan analisis data dan diperiksa apakah kesimpulan sesuai dengan hipotesis, maksud dan tujuan penelitian.

\subsection{Instrumen Penelitian}

Adapun jenis insturmen yang digunakan dalam keempat pairwise Comparisson antar kriteria. penelitian ini, yaitu: a) menyebarkan lembar kuesioner yang diberikan kepada Kaprog. Akuntansi, Kaprog. Administrasi Perkantoran, Kaprog. Broadcast dan Guru Bimbingan Konseling di SMK untuk memperoleh dat yang digunakan dalam penerapan metode Analytical T Hierarchy Process (AHP). b) Menggunakan sebuah Minat-Potensi aplikasi expert choice yang digunakan peneliti untuk NilaiTesmengolah data hasil kuesioner dan akan menghasilkan potensi sebuah statistik yang membantu peneliti untuk menyelesaikan sistem pendukung keputusan menggunakan metode AHP; c) menentukan Bobot penilaian dari beberapa responden dalam suatu kelompok dirata-ratakan dengan rata-rata geometrik penilaian (Geometric Mean). Tujuannya adalah untuk mendapatkan sebuah nilai tunggal yang mewakili sejumlah responden. Rumus rata-rata geometrik adalah sebagai berikut:

$\mathrm{G}$ : Rata-rata geometrik

$x_{n}$ : Penilaian ke 1,2,3...n

$\mathrm{n}$ : Jumlah Penelitian

Pertanyaan-pertanyaan dari kuesioner yang merupakan instrumen variabel pada model AHP (Analytical Hierarchy Process) diukur dengan menggunakan skala penilaian hirarki dengan nilai skala pengukuran nominal 1-9.

\section{Hasil dan Pembahasan}

Dalam pembahasan struktur hierarchy pada metode AHP, terdapat 3 Objek yang harus di tentukan, yaitu Goal, Kriteria, dan Alternatif yang akan membantu peneliti untuk mendapatkan hasil dari permasalahan yang dibahas. Pada gambar 1 dibawah ini adalah merupakan struktur Hierarki dari Pemilihan Jurusan siswa di SMK.

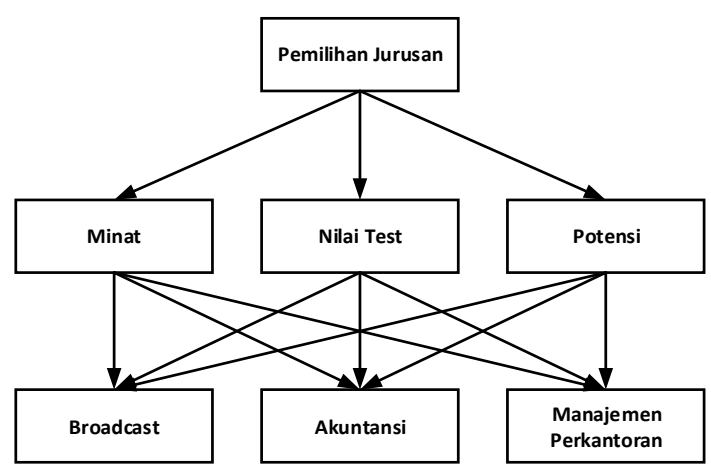

Gambar 1. Struktur Hierarki AHP Pemilihan Jurusan

Pada bagian berisi penjelasan ilmiah dari hasil penerapan metode penelitian yang telah ditetapkan.

Setiap perbandingan kriteria yang sama pada hasil Tabel 1. Perhitungan Geometrik Menggunakan Ms.Excel

\begin{tabular}{|c|c|c|c|c|c|}
\hline $\begin{array}{c}\text { perbandingan } \\
\text { kriteria }\end{array}$ & $\begin{array}{c}\text { kaprog } \\
\text { BC }\end{array}$ & $\begin{array}{c}\text { kaprog } \\
\text { AK }\end{array}$ & $\begin{array}{c}\text { kaprog } \\
\text { AP }\end{array}$ & $\begin{array}{l}\text { guru } \\
\text { BK }\end{array}$ & $\begin{array}{c}\text { Pembobot } \\
\text { an }\end{array}$ \\
\hline Minat-Nilai & & & & & \\
\hline Tes & 3 & 3 & 5 & 5 & 1,732051 \\
\hline Minat-Potensi & 4 & 3 & 1 & 2 & 2,213364 \\
\hline $\begin{array}{l}\text { NilaiTes- } \\
\text { potensi }\end{array}$ & 5 & 5 & 7 & 5 & 2,055668 \\
\hline
\end{tabular}


Didalam pengecekan konsistensi data pada tabel 1 Penentuan Bobot Antar Alternatif Berdasarkan Kriteria diatas, digunakan derajat kesalahannya adalah $10 \%$ Nilai Tes

dimana berarti CR harus kurang dari 0,1. Berdasarkan Comparisson Antar Kriteria dapat dilihat incon/ Consistency Ratio pada Pairwise Comparisson Antar Kriteria (Responden 1) adalah 0,08, pada gambar Pairwise Comparisson Antar Kriteria (Responden 2) adalah 0,04, pada Pairwise Comparisson Antar Kriteria (Responden 3) adalah 0,01, pada Pairwise Comparisson Antar Kriteria (Responden 4) adalah 0,05 dan pada Pairwise Comparisson Antar Kriteria (Combined) adalah sebesar 0,04. Maka dari itu preferensi pembobotan adalah konsistensi.
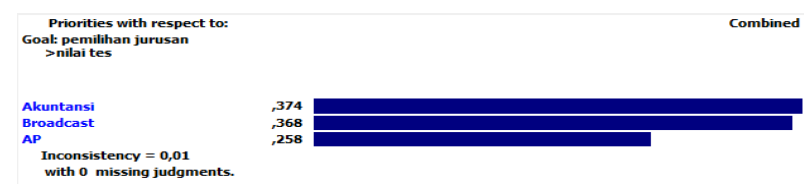

Gambar 3. Grafik Normalisasi Matriks Antar Alternatif Berdasarkan Kriteria Nilai Tes

Didalam gambar 3, setiap alternatif mendapatkan nilainilai pembobotan berdasarkan kriteria nilai tes setiap Jurusan. Broadcast mendapatkan bobot 0,368 atau $36,8 \%$, Akuntansi mendapatkan bobot 0,374 atau $37,4 \%$ dan Administrasi Perkantoran mendapatkan bobot 0,258 atau $25,8 \%$. Jika semua bobot ini ditambahkan atau dijumlahkan akan mendapatkan 0,100 atau $100 \%$. Didapat kesimpulan, bobot Alternatif (Vector Priority) Broadcast adalah 0,368; bobot combined Alternatif (Vector Priority) Akuntansi adalah 0,374; dan bobot Alternatif (Vector Priority) Administrasi Perkantoran adalah 0,258

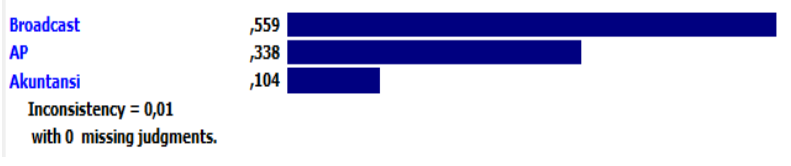

Gambar 2. Grafik Normalisasi Matriks Antar Alternatif Berdasarkan Kriteria Minat

Perhitungan nilai konsistensi Antar Alternatif Berdasarkan Kriteria Nilai Tes, dengan menentukan

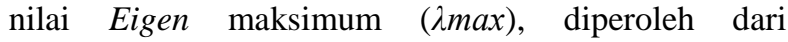
menjumlahkan seluruh hasil perkalian antara bobot kriteria (Vector Priority) dengan jumlah matriks Pairwise Comparisson.

$\lambda \max =((2,765 \mathrm{x} 0,368)+(2,650 \times 0,374)+(3,890 \times$

Didalam gambar 2, setiap alternatif mendapatkan nilai- 0,258)) =3,012. Mendapatkan nilai Indeks Konsistensi nilai pembobotan berdasarkan kriteria Minat setiap $(\mathrm{CI})$, dengan menghitung $\mathrm{CI}=(3,012-3) /(3-1)=0,006$ Jurusan. Broadcast mendapatkan bobot 0,559 atau Mendapatkan nilai Rasio Konsistensi (CR), dengan 55,9\%, Akuntansi mendapatkan bobot 0,104 atau menghitung $\mathrm{CR}=\mathrm{CI} / \mathrm{RI}$, nilai RI untuk $\mathrm{n}=3$ adalah $10,4 \%$ dan Administrasi Perkantoran mendapatkan 0,58. CR $=\mathrm{CI} / \mathrm{RI} \rightarrow 0,006 / 0,58=0,01$ (dengan bobot 0,338 atau 33,8\%. Jika semua bobot ini kesimpulan adalah konsisten). Grafik Normalisasi ditambahkan atau dijumlahkan akan mendapatkan Antar Alternatif Berdasarkan Kriteria Nilai Tes adalah 0,100 atau $100 \%$. Didapat kesimpulan bahwa bobot benar.

alternatif (Vector Priority) Broadcast adalah 0,558;

bobot alternatif (Vector Priority) Akuntansi adalah Penentuan Bobot Antar Alternatif Berdasarkan Kriteria 0,104; dan bobot alternatif (Vector Priority) Potensi

Administrasi Perkantoran adalah 0,338.

Mendapatkan perhitungan konsistensi antar Alternatif Berdasarkan Kriteria Minat, dengan cara menentukan nilai Eigen maksimum ( $\lambda$ max), yang diperoleh dari menjumlahkan seluruh hasil perkalian antara bobot kriteria (Vector Priority) dengan jumlah matriks Pairwise Comparisson.

$\lambda \max =((1,746 \mathrm{x} 0,558)+(9,448 \times 0,104)+(3,134 \times$ $0,338))=3,018$. Didapatkan nilai Indeks Konsistensi (CI), dengan menghitung $\mathrm{CI}=(3,018-3) /(3-1)=0,009$ Mendapatkan nilai Rasio Konsistensi (CR), dengan menghitung $\mathrm{CR}=\mathrm{CI} / \mathrm{RI}$, nilai $\mathrm{RI}$ untuk $\mathrm{n}=3$ adalah $0,58 . \mathrm{CR}=\mathrm{CI} / \mathrm{RI} \rightarrow 0,009 / 0,58=0,015 \Rightarrow 0,01$ (dengan kesimpulan adalah Konsisten). Grafik Normalisasi Antar Alternatif Berdasarkan Kriteria Minat adalah benar. Goal: pemilihan jurusan

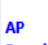
Kriteria Potensi

Didalam gambar 4, setiap alternatif mendapatkan nilainilai pembobotan berdasarkan kriteria potensi setiap Jurusan. Broadcast mendapatkan bobot 0,329 atau $32,9 \%$, Akuntansi mendapatkan bobot 0,290 atau 29\% dan Administrasi Perkantoran mendapatkan bobot 0,381 atau $38,1 \%$. Jika semua bobot ini ditambahkan atau dijumlahkan akan mendapatkan 0,100 atau $100 \%$. Didapat kesimpulan bobot alternatif (Vector Priority)
Priorities with respect to: Combined 
Broadcast adalah 0,330; bobot alternatif (Vector Gambar 6 menjelaskan perhitungan persentase Priority) Akuntansi adalah 0,290; dan bobot alternatif alternatif dan masing-masing level.

(Vector Priority) Administrasi Perkantoran adalah 0,381

Hasil Synthesis With Respect, seperti gambar 7.

Perhitungan konsistensi antar alternatif berdasarkan kriteria potensi, dengan menentukan nilai Eigen maksimum ( $\lambda$ max) yang diperoleh dari menjumlahkan seluruh hasil perkalian antara bobot kriteria (Vector Priority) dengan jumlah matriks Pairwise Broadcast Comparisson. $\lambda \max =((3,073 \mathrm{x} \quad 0,330)+(3,446 \quad \mathrm{x}$ Akuntansi $0,290)+(2,624 \times 0,3381))=3,010$

Mendapatkan nilai indeks konsistensi (CI), dengan menghitung $\mathrm{CI}=(3,010-3) /(3-1)=0,005$

Mendapatkan nilai Rasio konsistensi (CR), dengan Gambar 7, merupakan hasil dari perhitungan menghitung $\mathrm{R}=\mathrm{CI} / \mathrm{RI}$, nilai RI untuk $\mathrm{n}=3$ adalah 0,58 keseluruhan Analytical Hierarchy Process untuk $\mathrm{CR}=\mathrm{CI} / \mathrm{RI} \rightarrow=0,005 / 0,58=0,01$ (dengan pemilihan jurusan.

kesimpulan adalah konsisten). Grafik Normalisasi Antar Alternatif Berdasarkan Kriteria Potensi adalah benar.

\subsection{Perhitungan Hasil Pengolahan Analytical Hierarchy Process}

Setelah mendapatkan nilai masing-masing dari setiap pembobotan kriteria dan setiap alternatif berdasarkan kriteria. Langkah terakhir bisa dilihat pada gambar 5 dibawah yang harus dilakukan untuk memilih jurusan pada SMK adalah menghitung nilai aggregate masingmasing Jurusan yang dijadikan alternatif. Nilai aggregate diperoleh dari dengan cara mengalikan nilai
bobot setiap kriteria dengan nilai bobot setiap alternatif jurusan dengan kriteria yang sama.

\begin{tabular}{|c|c|c|}
\hline Level 1 & Alts & Prty \\
\hline \multicolumn{3}{|l|}{ Percent minat (L: 0.337 ) } \\
\hline \multirow{3}{*}{ minat (L: 0.337) } & Broadcast & .143 \\
\hline & Akuntansi & .026 \\
\hline & $\mathrm{AP}$ & .086 \\
\hline \multirow[t]{2}{*}{ Percent nilai tes (L: 0.475 ) } & & 53,7 \\
\hline & Broadcast & .197 \\
\hline \multirow[t]{2}{*}{ nilai tes $(L: 0,475)$} & Akuntansi & 201 \\
\hline & $\mathrm{AP}$ & .138 \\
\hline \multirow[t]{2}{*}{ Percent potensi (L: 0.188 ) } & & 20,8 \\
\hline & Broadcast & .069 \\
\hline \multirow[t]{2}{*}{ potensi (L: 0,188) } & Akuntansi & .060 \\
\hline & $\mathrm{AP}$ & .079 \\
\hline
\end{tabular}

Gambar 5. Hasil Penilaian Akhir Menggunakan Expert Choice

\subsection{Pembahasan Dari Hasil Pengolahan Analytical} Hierarchy Process

Berikut ini adalah grafik dan hasil akhir dari perhitungan Pemilihan Jurusan.

Tabel 2. Hasil Akhir Perhitungan Pemilihan Jurusan

\begin{tabular}{cccccc} 
HASIL & & & & & \\
GOAL & Minat & Nilai Tes & Potensi & JML & TOTAL \\
\cline { 2 - 6 } BOBOT & $34 \%$ & $47 \%$ & $19 \%$ & $100 \%$ & $100 \%$ \\
Broadcast & 0,18972 & 0,173 & 0,0627 & 0,42538 & $43 \%$ \\
Akuntansi & 0,03536 & 0,17578 & 0,0551 & 0,26624 & $27 \%$ \\
AP & 0,11492 & 0,12126 & 0,07239 & 0,30857 & $31 \%$ \\
& & & & & $100 \%$
\end{tabular}

Berikut disajikan dari data tabel 2 dalam bentuk grafik, seperti gambar 8 .

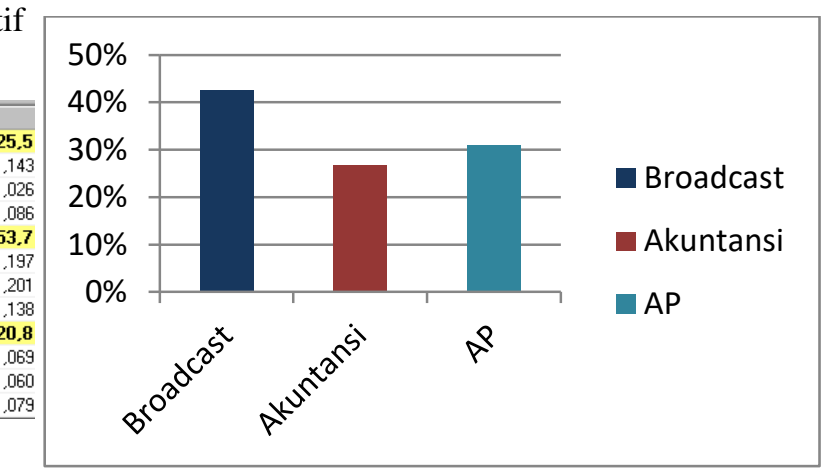

Gambar 8. Grafik Pemilihan Jurusan

Gambar 8 menunjukan tingkat perbandingan hasil Setelah Pengelolaan dan Perhitungan data selesai yang didapat dengan menggunakan metode AHP untuk dilakukan, kemudian diperoleh hasil seperti gambar 6 memilih jurusan yang tepat. Sebagai hasil didapat ada seperti berikut:

\begin{tabular}{|c|c|c|}
\hline Alts & Level 1 & Prty \\
\hline \multirow[t]{2}{*}{ Percen... } & & 28.7 \\
\hline & minat $(L: 0,337)$ & .026 \\
\hline \multirow[t]{2}{*}{ Akkuntansi } & nilai tes $(L: 0,475)$ & .201 \\
\hline & potensi $(L: 0,188)$ & .060 \\
\hline \multirow[t]{2}{*}{ Percen... } & & 30,3 \\
\hline & minat $(L: 0,337)$ & .086 \\
\hline \multirow[t]{2}{*}{ AP } & nilai tes $(L: 0,475)$ & .138 \\
\hline & potensi $(L: 0,188]$ & .079 \\
\hline \multirow[t]{2}{*}{ Percen.. } & & 40,9 \\
\hline & minat (L: 0,337$)$ & .143 \\
\hline \multirow[t]{2}{*}{ Broadcast } & nilai tes $(L: 0,475)$ & .197 \\
\hline & potensi (LL: 0,188$)$ & .069 \\
\hline
\end{tabular}

Gambar 6. Hasil Perhitungan Penilaian Akhir jurusan yang tepat adalah Broadcasting. Diasumsikan jaman perkembangan saat ini media semakin berkembang maka jurusan Broadcasting banyak siswa SMK yang memilih.

\section{Kesimpulan}

5.1 Simpulan

Terdapat 3 kriteria perbandingan yang digunakan di SMK untuk pemilihan jurusan, yaitu : Minat, Nilai Tes dan potensi. Hasil analisis dari perhitungan hasil

Jurnal RESTI (Rekayasa Sistem dan Teknologi Informasi) Vol . 2 No. 3 (2018) 662 - 667 
Analytical Hierarchy Process menyatakan bahwa yang dibuat dapat dikembangkan lebih lanjut atau alternatif yang terpilih dan paling sesuai dengan kriteria sebagai penelitian untuk hasil yang lebih baik lagi. adalah Broadcast. Dengan hasil AHP yang diperoleh dari 3 responden yang kemudian dihitung dan didapat Daftar Rujukan hasil akhir bahwa Broadcast unggul dengan presentase nilai sebesar $43 \%$ berbanding dengan Akuntansi 27\% dan Administrasi Perkantoran 31\%. Secara global faktor utama yang paling di prioritaskan dalam penilaian pemilihan jurusan adalah nilai tes dengan nilai bobot 0,473 atau $47 \%$ dan jurusan yang paling di prioritaskan adalah jurusan Broadcast dengan nilai 47\%. Metode Analytical Hierarchy Process dapat membantu sekolah khususnya untuk menentukan beberapa persoalan mengenai pemilihan jurusan. Karena metode AHP yaitu suatu metode yang input utamannya adalah persepsi manusia. Penyelesaian kasus metode AHP, responden bisa ditambahkan sesuai kebutuhan, sedangkan kriteria dan alternatif hanya ditentukan dari masing-masing tempat dilakukannya penelitian.

\subsection{Saran}

Beberapa saran untuk penelitian lanjutan, dilihat dari [6] beberapa aspek, diantaranya 1) Aspek Manajerial, dengan melihat hasil penelitian ini dapat diterapkan di sekolah-sekolah lainnya. Agar dapat membantu sekolah dalam hal pengambilan keputusan; 2) Aspek Sistem, [7] dengan melihat konsistensi perlu diperhatikan pada pairwise comparisons (perbandingan berpasangan) agar tidak terjadi inkonsistensi dengan cara mengukur instrumen pertanyaan yang akan diajukan dalam kuesioner, konsistensi combined juga perlu diperhatikan karena terkadang 4 ahli memiliki hasil pemikiran yang berbeda yang dapat menyebabkan pairwise comparisons combined menjadi inkonsistensi; c) Aspek Penelitian, dengan melihat penelitian yang dilakukan ini berhubungan dengan keperluan SMK saat ini, sehingga untuk waktu, kondisi dan tempat yang berbeda perlu dilakukan penelitian lanjutan. Penelitian ini dapat dikembangkan lebih lanjut dengan menambah kriteria dan alternatif lainnya atau merubah sesuai dengan kebutuhan di sekolah untuk menyelesaikan hal hal yang bersangkutan. Sistem pendukung keputusan
[1] J. Haryanto and S. Hansun, "Pengembangan Aplikasi Pendukung Keputusan Pemilihan Program Studi dengan Metode Fuzzy Logic (Studi Kasus: Universitas Multimedia Nusantara)," Ultim. Comput., vol. 7, no. 1, pp. 12-18, 2015.

[2] R. Rusdiansyah, "Analisis Keputusan Menentukan Jurusan Pada Sekolah Menengah Kejuruan Dengan Metode Simple Additive Weighting," J. Techno Nusa Mandiri, vol. 14, no. 1, pp. 49-56, Mar. 2017.

[3] A. Arifin, "Teknik Two Stay Two Stray Dalam Bimbingan Kelompok Untuk Meningkatkan Wawasan Siswa Dalam Pemilihan Jurusan Di Perguruan Tinggi," J. Psikol. Pendidik. dan Konseling J. Kaji. Psikol. Pendidik. dan Bimbing. Konseling, vol. 1, no. 1, p. 19, Aug. 2015.

[4] T. F. P. Siallagan, "Penentuan Program Studi Mahasiswa STKIP Subang dengan Algoritma C4.5," Tekno Efisiensi J. Ilm. KORPRI Kopertis WIllayah IV, vol. 1, no. 1, pp. 101-111, 2016.

D. Khuntari and R. Ferdiana, "Teknik Rekomendasi Pemilihan Jurusan Perguruan Tinggi dengan Pendekatan Preferensi Pengguna dan Analytic Hierarchy Process," Semin. Nas. Teknol. Inf. dan Multimed., vol. 3, no. 1, p. 2.2-25-2.2-30, 2015.

D. A. Latif, H. Hamdani, and Y. Yulianto, "Sistem Penunjang Keputusan Pemilihan Program Studi Di Universitas Mulawarman Menggunakan Metode Promethee," Inform. Mulawarman J. Ilm. Ilmu Komput., vol. 8, no. 2, pp. 61-64, Jun. 2016.

[7] L. Swastina, "Penerapan Algoritma C4.5 Untuk Penentuan Jurusan Mahasiswa," J. GEMA Aktual., vol. 2, no. 1, pp. 9398, 2013.

[8] D. T. Budianto and A. Irawan, "Sistem Pendukung Keputusan untuk Menentukan Jurusan Siswa Baru di SMK Negeri 1 Kragilan Menggunakan Metode Naive Bayes," ProTekInfo(Pengembangan Ris. dan Obs. Tek. Inform., vol. 1, no. 1, pp. 62-67, Jan. 2017.

[9] A. Wicaksono and N. Aminudin, "Perancangan Sistem Pendukung Keputusan Penentuan Jurusan Siswa Sma Pgri 2 Pringsewu Dengan Menggunakan Metode Analytical Hierarchy Proses (AHP)," PROCIDING KMSI, vol. 5, no. 1, pp. 16-24, Oct. 2017.

[10] A. A. Harahap, "Sistem Pendukung Keputusan Penentuan Jurusan Dengan Metode Analytical Hierarchy Process ( Studi Kasus: Smk Swasta Kartini Utama Sei Rampah )," Pelita Inform. Budi Darma, vol. 9, no. 2, pp. 13-20, 2015.

[11] B. Hartono, Sistem Informasi Manajemen Berbasis Komputer, 1st ed. Jakarta: Rineka Cipta, 2013.

[12] Kusrini, Konsep dan Aplikasi Sistem Pendukung Keputusan, vol., no. 2007. 